\title{
Employing the extended Kalman filter in measuring the output gap
}

\author{
Levent Ozbek $^{\mathrm{a}}$, Umit Ozlale ${ }^{\mathrm{b}, *}$ \\ ${ }^{a}$ Department of Statistics, Ankara University, Ankara, Turkey \\ ${ }^{\mathrm{b}}$ Department of Economics, Bilkent University, Bilkent, 06800, Ankara, Turkey
}

Received 5 March 2004; accepted 21 September 2004

\begin{abstract}
The paper has two parts. In the first part, the output gap and potential output series for the Turkish economy are derived within the context of a non-linear state space model, where the extended Kalman filter emerges as the estimation methodology. Such a methodology allows for time-varying parameters to decompose output into trend and cyclical components. The results imply that both the parameters in the model and the derived series are fairly reasonable and consistent with the path that the Turkish economy followed in the last fifteen years. In the second part, the relation between inflation and the output gap is analyzed. It is found that inflation and the output gap are not positively associated, contradicting studies that view demand side forces as the primary determinants of inflation in Turkey.
\end{abstract}

(C) 2004 Elsevier B.V. All rights reserved.

JEL classification: C32; C63; E30

Keywords: Extended Kalman filter; Output gap; Emerging economies

\section{Introduction}

A significant amount of work dedicated to the analysis of growth strategies, business cycles, and the stance of monetary and fiscal policies views both the output

\footnotetext{
*Corresponding author. Tel.: + 90312 2901584; fax: +903122665140.

E-mail address: ozlale@bilkent.edu.tr (U. Ozlale).
} 
gap and potential output as crucial macroeconomic variables. One reason for this importance is the information that these two related series contain both as measures of the aggregate supply side capacity of the economy and of the extent that aggregate demand may expand without accelerating inflation.

However, despite their importance, there are some difficulties encountered in measuring potential output and the output gap. One obvious reason is that potential output cannot be directly observed. Although these two series are derived from complex macroeconomic models for some industrialized countries, such models have not been developed yet for many emerging economies. Therefore, the studies that focus on these economies must rely on basic statistical procedures. Two widely used statistical methods that have been proposed for those kind of economies are Hodrick-Prescott (HP) filtering and quadratic time detrending. ${ }^{1}$ However, although these two methodologies do a good job in measuring potential output for industrialized economies, where an excessive boom-bust cycle along with volatile output are rarely observed, they usually cannot capture the very high volatility of macroeconomic variables in emerging market economies.

Another methodology, which seems not to overcome these problems, involves constructing an unobserved components model, for which the Kalman Filter emerges as the appropriate estimation algorithm. A seminal paper that analyzes the United States economy using this approach is Kuttner (1994), which was then extended by Gerlach and Smets (1999) using EMU data.

On the other hand, by allowing the parameters of an unobserved components model to vary over time, one might hope to capture much more of the volatility and structural change that seem to characterize the emerging market economies. In this case, where the state variables (including potential output and the output gap) and the time-varying system parameters need to be estimated simultaneously, the extended Kalman filter (EKF henceforth) becomes the appropriate estimation procedure. Although a powerful algorithm, the EKF has been employed in only a limited number of previous studies, such as Grillenzoni (1993), McKiernan (1996), Bacchetta and Gerlach, 1997, and Ozbek and Efe (2004).

This study takes the above discussion as its starting point and employs EKF in a non-linear time series framework to measure output gap and potential output for the Turkish economy between 1988 and 2003. The main reason for analyzing the Turkish economy is its volatile output performance, especially after the liberalization attempts intensified in the mid 1980s. Such attempts, combined with persistent inflation and lack of fiscal discipline surely make the Turkish case an interesting one.

Moreover, we believe that the findings in this paper will serve as a useful reference for future studies in two ways. First, on the technical side, we propose an alternative methodology where we employ an econometric model with time-varying parameters to decompose output into trend and cyclical components. Such an approach will not lead to a "too-smooth trend", which is a criticism made for HP filter or a quadratic time trend. Second, from a substantive perspective, our resulting measure of the

\footnotetext{
${ }^{1}$ Quadratic time detrending was mainly employed in studies concerning the United States economy, such as Cogley (1997) and Clarida et al. (1998).
} 
output gap can be employed to evaluate the performance of fiscal and monetary policy. The relationship between output gap and inflation will also reveal important information about the validity of Phillips curve and the dynamics of persistent inflation, which seems to be the most problematic macroeconomic variable for the Turkish economy.

The next section introduces both the econometric model and the estimation methodology to be employed. Then, the estimated results are compared with those obtained from alternative methods and interpreted based on the performance of the Turkish economy. The final section concludes.

\section{The model}

Consistent with Denis et al. (2002), it is assumed that actual output can be decomposed into two components, trend and cycle, such that

$$
Y_{k}=T_{k}+C_{k},
$$

where $T_{k}$ and $C_{k}$ denote the trend and cycle at time $k$, respectively. The cycle $C_{k}$, as the deviation of actual output from its trend, will then serve as the output gap series. The two components are distinguished by their differing time-series behavior. The cyclical component $C_{k}$ is assumed to follow a second-order autoregressive process with a disturbance that has zero mean and a constant variance. Also, and importantly, we allow the autoregressive parameters for the cycle to vary over time; more specifically, they are assumed to follow independent random walks. Formally,

$$
\begin{aligned}
& C_{k}=\gamma_{1, k} C_{k-1}+\gamma_{2, k} C_{k-2}+\varepsilon_{k}, \\
& \gamma_{1, k}=\gamma_{1, k-1}+\zeta_{\gamma 1, k}, \\
& \gamma_{2, k}=\gamma_{2, k-1}+\zeta_{\gamma 2, k} .
\end{aligned}
$$

It is assumed that $\varepsilon_{k}$, $\zeta_{\gamma 1, k}$ and $\zeta_{\gamma 2, k}$ are all i.i.d. with zero means and constant variances.

Finally, we specify the trend component as a random walk with drift

$$
\begin{aligned}
& T_{k}=\mu_{k}+T_{k-1}+z_{k}, \\
& \mu_{k}=\mu_{k-1}+\zeta_{a, k}
\end{aligned}
$$

where the disturbances $z_{k}$ and $\zeta_{a, k}$ again are i.i.d. with zero means and constant variances. ${ }^{2}$ The random walk with drift assumption, which implies that shocks to trend output are permanent, needs to be explained. In a recent study, Aguiar and Gopinath (2004) state that emerging markets are subject to extremely volatile shocks to the stochastic trend and provide evidence that emerging market business cycles are driven by those shocks, which may result from extreme and relatively frequent

\footnotetext{
${ }^{2}$ Different specifications are attempted to explain both cycle and the trend in Eqs. (1)-(6). However, the results did not change significantly.
} 
changes in economic policies, peculiar to emerging markets. Therefore, Eqs. (5) and (6) are consistent with Aguiar and Gopinath's notion that "The Cycle is The Trend".

As mentioned above, our exercise differs from Denis et al. (2002) and other previous studies by allowing for time-varying parameters in the decomposition of output into trend and cyclical components. Using a model without time-varying parameters, Denis et al. (2002) must confront the problem of finding too smooth estimated trends. To overcome this problem, they impose a strong restriction by fixing the variance of the estimated trend, as suggested by Gordon (1997). However, as shown below, these restrictions need not be imposed when employing the extended Kalman filter. It is shown that stability is achieved and the estimated parameters along with the derived series are fairly reasonable.

\subsection{Estimation procedure: $E K F$}

The Kalman filter, introduced by Kalman (1960) solves the problem of estimating the instantaneous states of a linear dynamic system perturbed by Gaussian white noise, using measurements that are linear functions of the system state but corrupted by additive white noise. Therefore, it is the appropriate estimation procedure for state space systems. Here, however, where the state variables and the time-varying parameters need to be simultaneously estimated, the problem of nonlinearity emerges, ruling out the use of the standard Kalman filter and necessitating the use of the extended Kalman filter. This algorithm applies the standard Kalman filter equations to the first-order approximation of the nonlinear model about its last estimate. Both the extended Kalman filter algorithm and its application in non-linear state space models are discussed by Chui and Chen (1991) and Chen (1993) in detail.

\section{Estimation results}

Seasonally adjusted quarterly real GDP is employed for the period between 1988:01 and 2003:2. The ADF test statistic for the seasonally adjusted quarterly real GDP is -2.69 and the null hypothesis of a unit root cannot be rejected. Such a finding rationalizes the random walk with a drift choice for the trend component. The actual output along with estimated potential output and the output gap series can be seen in Figs. 1 and 2, respectively. As can be seen in the output gap series, the two major financial crisis in April 1994 and February 2001 are nicely captured along with the negative impact of the Russian crisis and the devastating earthquake in August 1999. More discussions about output gap and its relationship with inflation is presented below. Next, the $\mathrm{AR}(2)$ assumption about $C_{k}$ is tested. The lowest Schwarz criteria and the highest F-statistic is obtained under an AR(2) specification for the estimated cycle term. Also, the Breusch-Godfrey Lagrange Multiplier test shows that the null hypothesis of no serial correlation in the residuals cannot be rejected under such a specification.

Figs. 3 and 4 show the evolution of the time-varying parameters $\gamma_{1, k}$ and $\gamma_{2, k}$. It is important to note that, although no restrictions are imposed about the stability of 


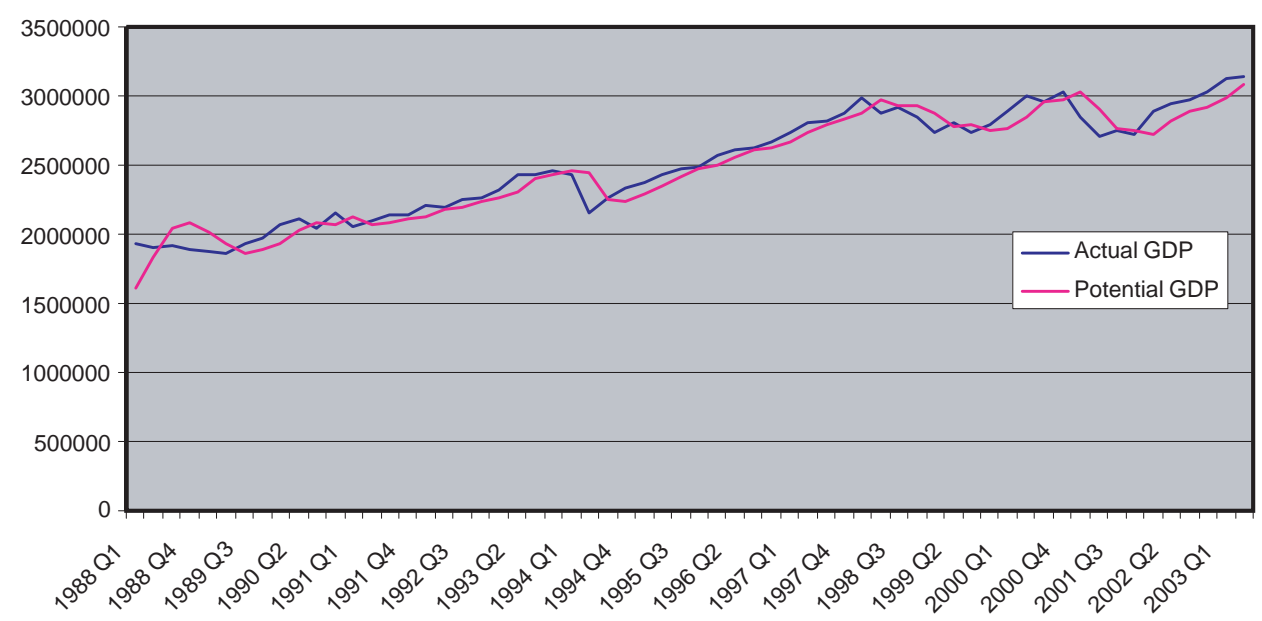

Fig. 1. Actual and potential GDP.

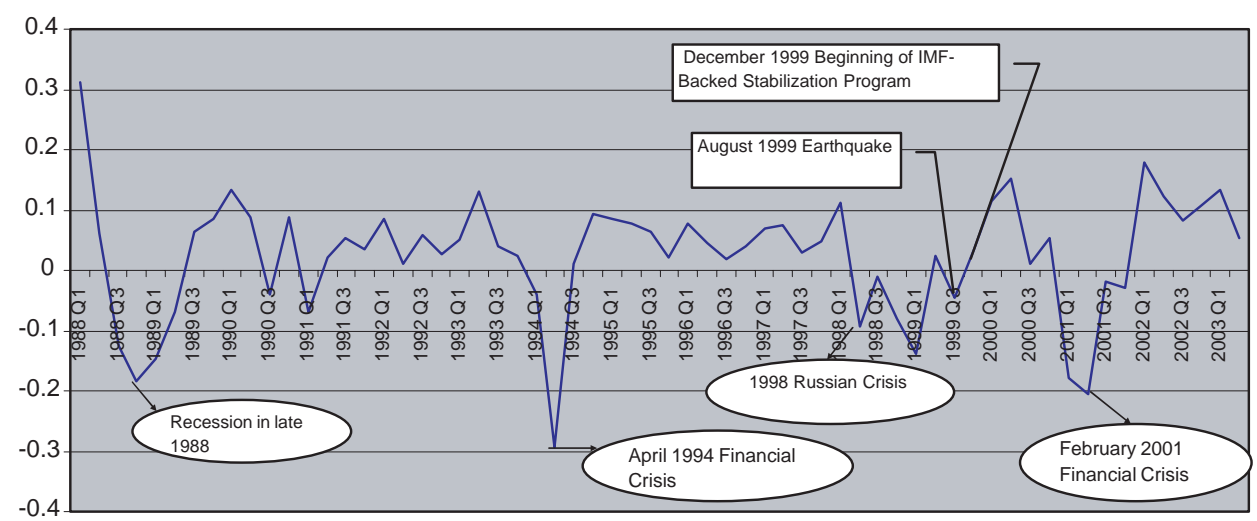

Fig. 2. Output gap.

the system, which would require $\left|\gamma_{1, k}+\gamma_{2, k}\right|<1$, the sum of the parameters does not exceed unity for each time period, implying that the system is stable. On the other hand $\mu_{k}$, which is the drift in the trend equation, is displayed in Fig. 5 and it takes values between -0.5 and +0.5 . As a result, all of the parameters, the state variables and the derived series seem to be reasonable. As a final check, the mean of the residuals in Fig. 6 is found to be -0.003 with a standard deviation of 0.09 .

\subsection{Comparison with HP filtering}

In the following two sections, both the potential output and the output gap series derived above are compared with the ones that are obtained with the HP filter and the standard Kalman filter. 


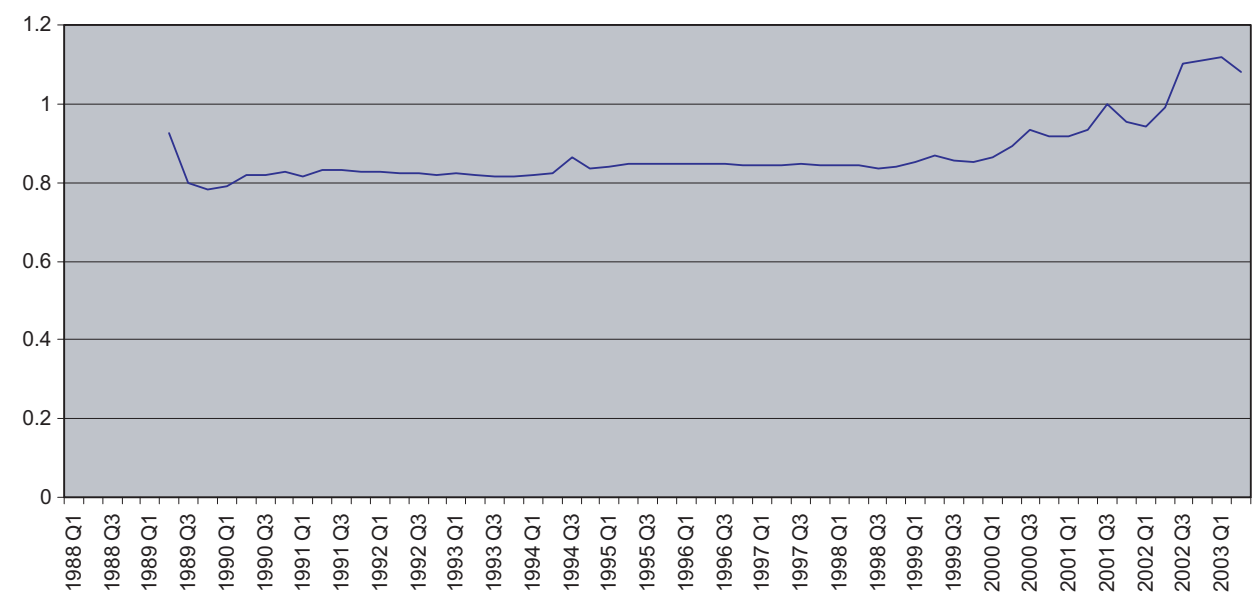

Fig. 3. Parameter $\gamma_{1}$.

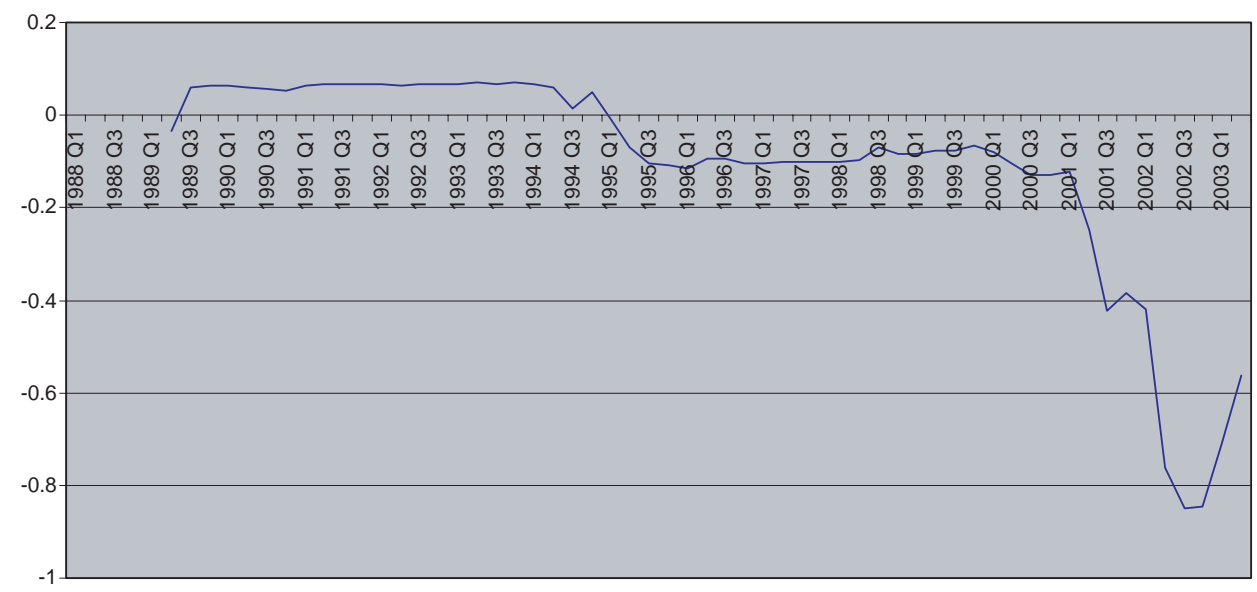

Fig. 4. Parameter $\gamma_{2}$.

The HP filter can be viewed as two-sided moving average filter, where its moving average coefficients are functions of a "smoothness" parameter for the trend component. Although it is widely used in obtaining potential output estimates, it has also been subject to serious criticisms. As an example, Laxton and Tetlow (1992) show that the HP filter provides an imprecise estimate of potential output. Also, Harvey and Jaeger (1993) argue that the HP filter may introduce spurious features in its estimate of the trend and add that conditions required for the HP filter to serve as an optimal filter are rarely met in practice. A common result documented in these studies is that although the potential output estimates that employ HP filter may provide accurate results for countries like the United States, a more general and flexible procedure should be developed for other economies, where potential output 


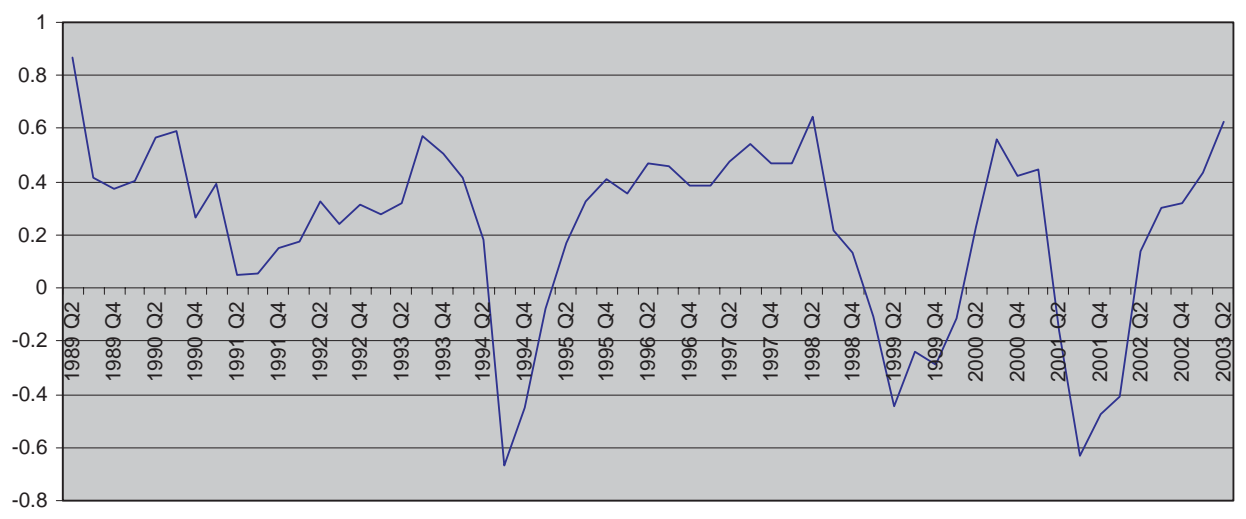

Fig. 5. Drift in the trend, $\mu$.

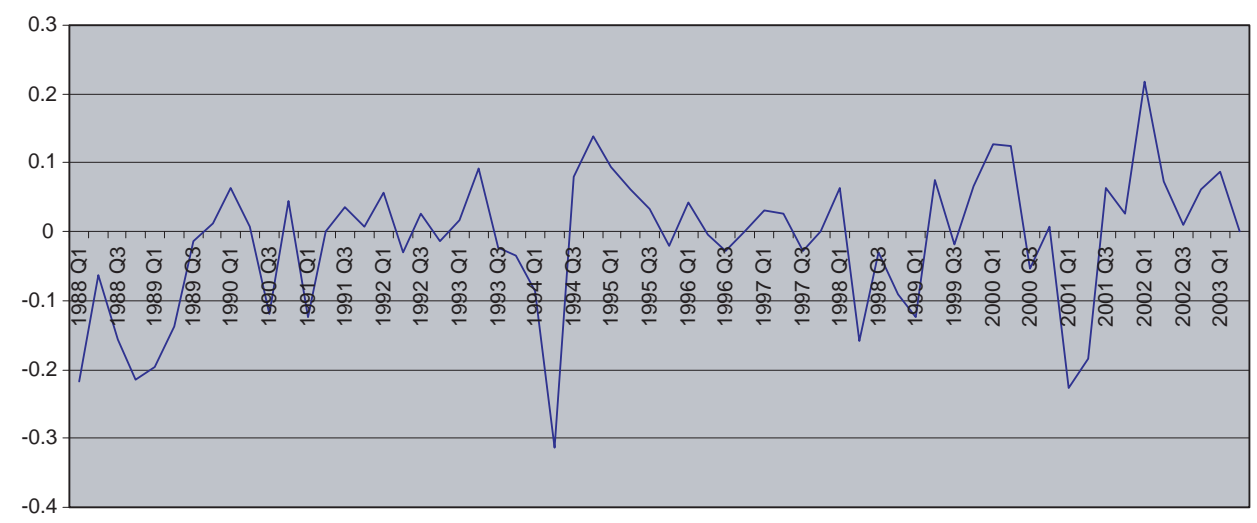

Fig. 6. Residuals.

does not follow a smooth trend. Actually, Fig. 7, where two potential output estimates are presented along with actual output, validates these arguments. There, it is evident that the HP filter cannot capture the excessive boom-bust cycle along with volatile output, which is a well-known characteristic of many emerging markets, including the Turkish economy.

\subsection{Comparison with standard Kalman filtering}

As discussed above, the standard Kalman filter procedure is inappropriate due to non-linearity when both the time-varying parameters and the state variables need to be simultaneously estimated. Therefore, in order to execute the standard Kalman filter and compare the results, we have to treat the parameters $\gamma_{1, k}$ and $\gamma_{2, k}$ as constant through time. After the standard Kalman filtering procedure is followed, 


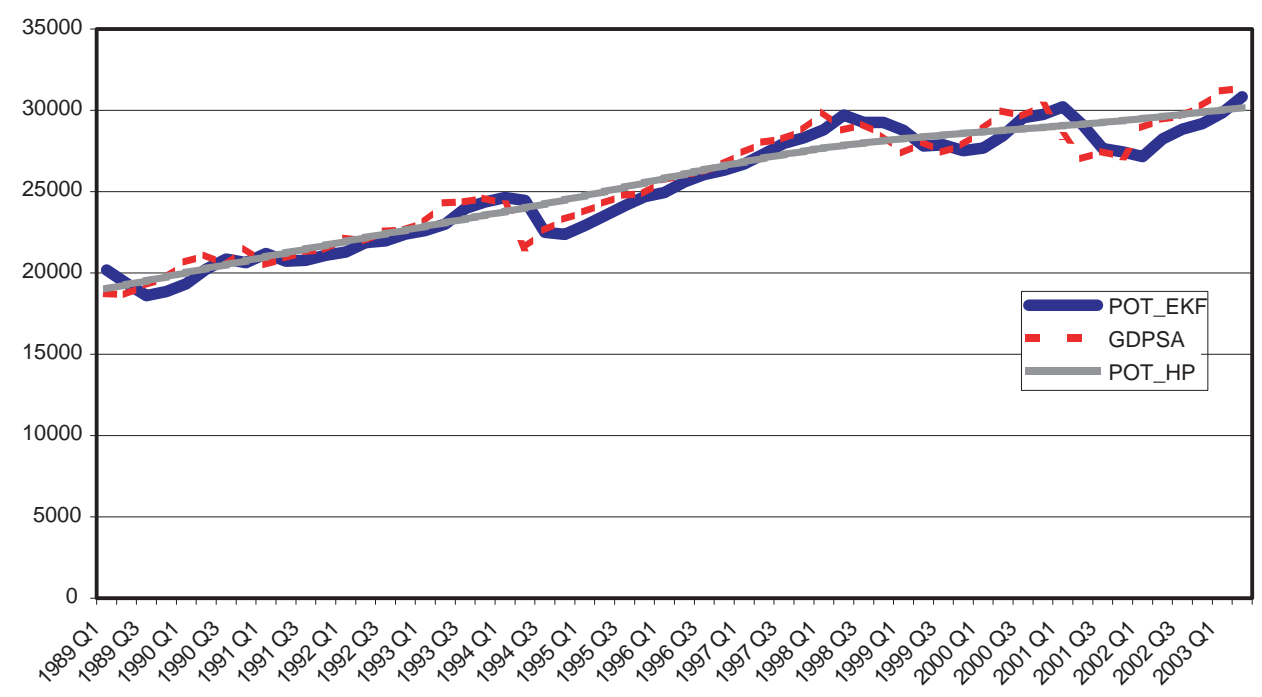

Fig. 7. Comparison.

the estimates for these parameters are found as 0.78 and 0.09 , respectively. The comparison of three gap measures are displayed in Fig. 8. There, it can easily be seen that the output gap measure derived from the standard Kalman filter procedure provides imprecise results and is not consistent with recent observations. For example, it implies that the Turkish economy had a positive output gap in the first quarter of 2001 and did not experience the negative effects of the February 2001 financial crisis until the last quarter of that year. Evidently, treating parameters as constant in the standard Kalman filtering procedure is inferior to allowing parameters to vary over time.

\subsection{Interpreting the output gap}

In this section, to see the implications of the Phillips Curve for the Turkish economy, the relationship between inflation and output gap is analyzed. Before analyzing this relationship, it is necessary to evaluate the boom-bust cycle experienced in the last fifteen years with the help of the derived output gap series.

\subsubsection{A brief overview of the Turkish economy}

At the beginning of 1988, the efforts for structural adjustment of the economy failed and the Turkish economy entered into a phase where growth performance was, at best, sluggish. As noted in Ertugrul and Selcuk (2001), unsuccessful disinflationary efforts and debt financing policies governed the dynamics of output and growth performance after this period. In the second half of 1988, the Turkish economy experienced a minor recession which lasted for about a year. The magnitude of this recession can also be seen in Fig. 2. After a few periods of high growth rates, a minor 


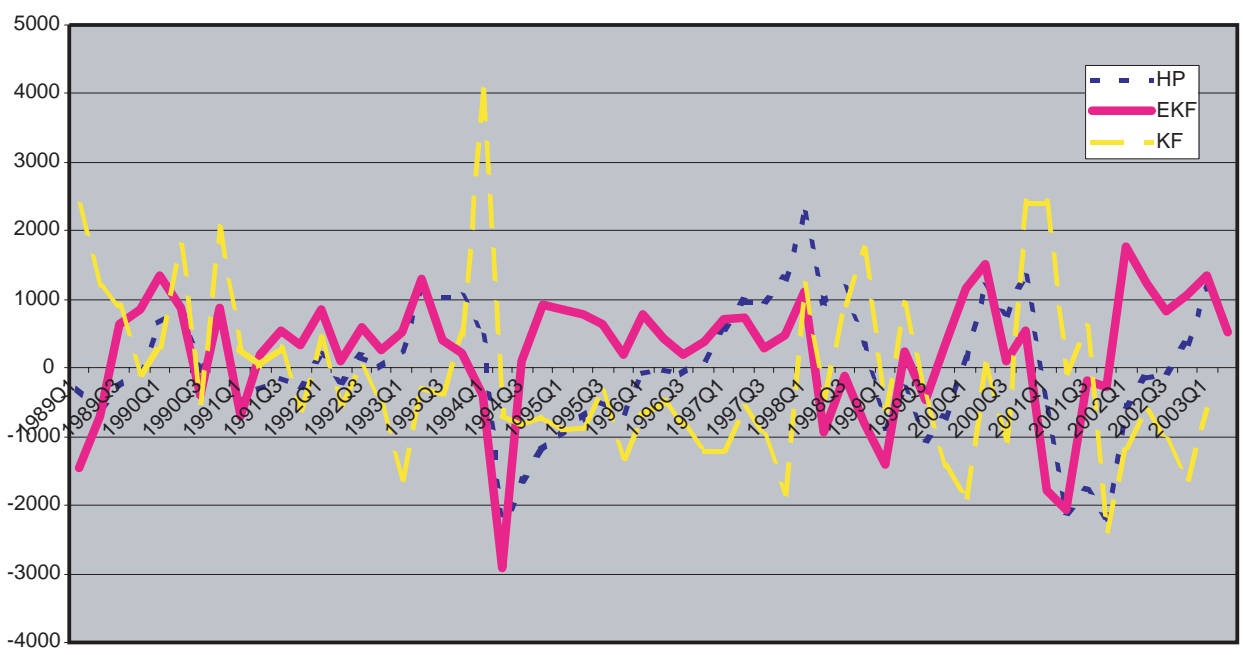

Fig. 8. Comparison of gap measures.

recession was felt again in the first quarter of 1991. However, the impacts of these two contractionary periods on the economy as a whole were not as big as the financial crisis in 1994, which resulted mainly from the unsustainable nature of fiscal policy and external deficit. From the second half of this year to the stabilization program in July 1998, the economy experienced moderate growth rates. Combined with the intensified political instability and the Russian crisis in 1998, the stabilization program failed and the economy re-entered into a recession. The devastating earthquake in August 1999 lengthened this contractionary period, which is clearly displayed in Fig. 2. Finally, an extensive disinflation program was initiated in December 1999, backed and supervised by International Monetary Fund (IMF). The program exclusively relied on a nominally anchored exchange rate basket and fiscal austerity. However, consistent with most of the exchange rate-based stabilization programs, the high growth rates coupled with an increased aggregate demand and a surge in consumption in the first phases of the program were followed by current account imbalances and a currency crisis. As a result, in February 2001, triggered with a political crisis, the Turkish economy entered into the deepest financial crisis of its history, which is also evident in Fig. 2.

Consequently, the output and growth dynamics for the Turkish economy, which resemble a boom-bust cycle, are clearly reflected in the derived output gap series in this paper. The next step is to have a quick look at the relationship between inflation and the output gap.

\subsubsection{Inflation and the output gap}

The Turkish economy experienced a high and persistent inflationary environment, beginning from the mid 1980s. Therefore, it is not surprising to see a vast literature 
Table 1

Correlation between inflation and output gap

\begin{tabular}{lccc}
\hline & Inflation & Output gap & Output gap $(-1)$ \\
\hline Inflation & 1.00 & -0.43 & -0.24 \\
Output gap & -0.43 & 1.00 & 0.41 \\
Output gap $(-1)$ & -0.24 & 0.41 & 1.00 \\
\hline
\end{tabular}

that is dedicated to explaining the inflation dynamics in Turkey. ${ }^{3}$ Most of these studies support the existence of a demand-pull inflation. Another common feature of this dense literature is that inflation is not closely or directly related to the output gap. ${ }^{4}$ However, the output gap is viewed as being one of the most important indicators of the stance of monetary policy and it also signals future policy changes. Moreover, a positive gap implies an over-heated economy, which further puts pressure on inflation. Therefore, if the views about inflation being determined by demand forces are correct, one should find a positive relation with output gap and inflation.

Based on the above discussion, we perform two simple exercises. First, we look at the correlation between output gap and inflation. Second, we perform a regression of inflation on the lagged value of the output gap after controlling for possible inflation inertia. As Table 1 clearly shows, both contemporaneous and lagged output gap are negatively correlated with inflation. Such a finding contradicts results from studies such as Yeldan (1993) and Metin (1995, 1998), which all support the idea of demandpull inflation.

Not surprisingly, the regression results support the above findings. After the sum of the coefficients on lagged values of inflation is restricted to unity, the estimated coefficient for the lagged value of the output gap is estimated as -0.07 . However, the coefficient is not statistically significant.

\section{Conclusion}

The output gap and potential output are vital concepts in explaining the aggregate supply side capacity of the economy and the extent to which aggregate demand may expand without accelerating inflation. However, the difficulties faced in developing proper measures for these two variables limit their usage in empirical work. These difficulties are even more problematic when emerging market economies are analyzed. These economies are mostly characterized by highly volatile output and rapidly changing macroeconomic dynamics. The conventional methods used most frequently to estimate the output gap, such as HP filtering and quadratic time

\footnotetext{
${ }^{3}$ See Kibritcioglu et al. (2002) for a detailed discussion of inflation in Turkey.

${ }^{4}$ Ozlale and Ozcan (2003) is an exception where inflation is explained in the context of a timeinconsistency problem.
} 
detrending, cannot generally capture this volatility and lead to the problem of finding too smooth trends.

This study takes the above discussion and the parametric model of output from Denis et al. (2002) as its starting point and derives potential output and output gap series for the Turkish economy between 1988 and 2003. We improve over the methodology in Denis et al. by introducing time-varying parameters into the model used to decompose output into trend and cycle components. Since the time-varying parameters and the state variables are estimated simultaneously, the model has a non-linear feature, so that the EKF emerges as the appropriate estimation method. Such an approach allows us to avoid the problem of finding a "too smooth trend" without having to resort to the strong restrictions that are imposed on the parameters in previous studies.

The results reveal that the estimated parameters are fairly reasonable. Even though no restrictions are imposed on the parameters, the system is found to be stable. More importantly, the output gap series can successfully explain most popular accounts of the path that the Turkish economy followed in the last fifteen years. The two major financial crises in April 1994 and February 2001 along with two minor recessions are nicely captured. Moreover, the derived series do not seem to have the overly smooth trend that previous studies have found.

As a final check, the relationship between inflation and the output gap is analyzed. There, we find that both contemporaneous and lagged values of the output gap are not positively associated with inflation. Such a finding contradicts both a Phillips curve notion and the more general view that demand side dynamics are the main determinant of inflation in Turkey.

In conclusion, we hope that the potential output and output gap series derived in this paper will conveniently be used in future studies that take the Turkish economy as a reference and attempt to link the output gap to other macroeconomic variables. Also, we hope that the reasonable parameter estimates obtained here imply that our EKF methodology can usefully be applied in other studies, using different data and different models.

\section{Acknowledgements}

We would like to thank Peter N. Ireland, Hakan Kara and two anonymous referees for their suggestions. The usual disclaimer applies.

\section{References}

Aguiar, M., Gopinath, G., 2004. Emerging market business cycles: the cycle is the trend. Mimeo, University of Chicago.

Bacchetta, P., Gerlach, S., 1997. Consumption and credit constraints: international evidence. Journal of Monetary Economics 40 (2), 207-238.

Chen, G., 1993. Approximate Kalman Filtering. World Scientific, Singapore.

Chui, C.K., Chen, G., 1991. Kalman Filtering with Real-Time Applications. Springer, Berlin. 
Clarida, R., Gali, J., Gertler, M., 1998. Monetary rules in practice: some international evidence. European Economic Review 42 (6), 1033-1067.

Cogley, T., 1997. Evaluating non-structural measures of the business cycle. FRB San Francisco Economic Review 3, 3-21.

Denis, C., Mc Morrow, K., Roger, W., 2002. Production function approach to calculating potential growth and output gaps - estimates for the EU member states and the U.S. European Commission Directorate - General for Economic and Financial Affairs Working Paper No:176, September 2002.

Ertugrul, A., Selcuk, F., 2001. A brief account of the Turkish economy, 1980-2000. Russian and East European Finance and Trade 37 (6), 6-30.

Gerlach, S., Smets, F., 1999. Output gaps and monetary policy in the EMU area. European Economic Review 43 (4-6), 801-812.

Gordon, R.J., 1997. The time-varying NAIRU and its implications for economic policy. Journal of Economic Perspectives 11 (1), 11-32.

Grillenzoni, C., 1993. ARIMA processes with ARIMA parameters. Journal of Business and Economic Statistics 11 (2), 235-250.

Harvey, A.C., Jaeger, A., 1993. Detrending, stylized facts and the business cycle. Journal of Applied Econometrics 8 (3), 231-247.

Kalman, R.E., 1960. A new approach to linear filtering and prediction problems. Journal of Basic Engineering 82, 35-45.

Kibritcioglu, A., Rittenberg, L., Selcuk, F., 2002. Inflation and Disinflation in Turkey. Ashgate Publishing, England.

Kuttner, K.N., 1994. Estimating potential output as a latent variable. Journal of Business and Economic Statistics 12 (3), 361-368.

Laxton, D., Tetlow, R., 1992. A simple multivariate filter for the measurement of potential output. Technical Report No:59, Bank of Canada, Ottawa.

McKiernan, B., 1996. Consumption and the credit market. Economics Letters 51 (1), 83-88.

Metin, K., 1995. An integrated analysis of Turkish inflation. Oxford Bulletin of Economics and Statistics 57 (4), 513-531.

Metin, K., 1998. The relationship between inflation and the budget deficit in Turkey. Journal of Business and Economic Statistics 16 (4), 412-422.

Ozbek, L., Efe, M., 2004. An adaptive extended Kalman filter with application to compartment models. Communications in Statistics-Simulation and Computation 33 (1), 145-158.

Ozlale, U., Ozcan, K.M., 2003. Does time inconsistency problem apply for Turkish monetary policy? Manuscript, Bilkent University, Department of Economics, Ankara, Turkey.

Yeldan, E., 1993. Conflicting interests and structural inflation: Turkey, 1980-1990. The Pakistan Development Review 32 (3), 303-327. 